\title{
THE UPPER BOUNDARY FOR THE RATIO BETWEEN $n$-VARIABLE OPERATOR POWER MEANS
}

\author{
YUKI SEO
}

Abstract. In this paper, we show estimates of the upper boundary for the ratio between $n$ variable operator power means $P_{t}(\omega ; \mathbb{A})$ due to Lawson-Lim-Pálfia by terms of a generalized condition number in the sense of Turing, which are partial improvements of the known results: Let $\mathbb{A}=\left(A_{1}, \ldots, A_{n}\right)$ be a $n$-tuple of positive invertible operators such that $m I \leqslant A_{j} \leqslant M I$ for $j=1, \ldots, n$ and $h=M / m$, and $\omega$ a weight vector. Then

$$
P_{t}(\omega ; \mathbb{A}) \leqslant\left(\frac{h^{t}+h^{-t}}{2}\right)^{1 / t} G_{K}(\omega ; \mathbb{A})
$$

for all $t \in(0,1]$, where $G_{K}(\omega ; \mathbb{A})$ is the Karcher mean.

Mathematics subject classification (2020): 47A63, 47A64.

Keywords and phrases: Operator power mean, geometric operator mean, Kantorovich constant, a generalized condition number, Karcher mean.

\section{REFERENCES}

[1] J. I. FuJil AND Y. SEO, On the Ando-Li-Mathias mean and the Karcher mean of positive definite matrices, Linear Multilinear Algebra, 63 (2015), 636-649.

[2] T. Furuta, J. Mićić Hot, J. Pečarić and Y. SeO, Mond-Pečarić Method in Operator Inequalities, Zagreb, Element, 2005, (Monographs in Inequalities 1).

[3] J. LAWSON AND Y. LIM, Karcher means and Karcher equations of positive definite operators, Trans. Amer. Math. Soc. Series B, 1 (2014), 1-22.

[4] Y. Lim ANd M. PÁLFIA, Matrix power means and the Karcher mean, J. Funct. Anal., 262 (2012), $1498-1514$.

[5] W. Specht, Zur Theorie der elementaren Mittel, Math. Z., 74 (1960), 91-98.

[6] M. TominagA, Specht's ratio in the Young inequality, Sci. Math. Japon., 55 (2002), 585-588.

[7] A. M. TuRING, Rounding off-errors in matrix processes, Quart. J. Mech. Appl. Math., 1 (1948), 287-308. 